\title{
Considerações sobre práticas pedagógicas do ensino de arte em cursos de formação de professores (Normal/Magistério)
}

\author{
Rosimara Albuquerque Mello \\ Fátima Maria Neves \\ Universidade Estadual de Maringá
}

\section{Resumo}

O objetivo deste artigo é o de apresentar e analisar os conteúdos e as práticas pedagógicas que se desdobraram no cotidiano das salas de aula, do Curso Normal e Magistério, do Colégio São Vicente de Paula, da cidade de Nova Esperança (PR), durante o período de 1971 a 1997. Justifica-se o recorte temporal mediante tal período corresponder à elaboração de Leis que impulsionaram o campo disciplinar da Arte bem como seu ensino. As Fontes empíricas que ampararam o estudo foram selecionadas por meio de Documentos Oficiais (Leis, Relatórios, Atas, Livros de Registros dos Professores) e Entrevistas semi-estruturadas com ex-professores e ex-alunos. Os argumentos analíticos destacam a impressão e a importância, para os agentes escolares -professoras e alunas da elaboração e utilização das "Pastas A-Z". As considerações finais destacam os problemas com o arquivamento das fontes para o desenvolvimento de pesquisas educacionais.

Palavras-chave: Educação; História da Educação Brasileira; Ensino de Arte; Formação de Professores.

\section{Abstract}

The aim of this article is to present and analyze the content and pedagogical practices that developed in everyday classrooms, the Normal Course and Teaching of Colégio Estadual São Vicente de Paula in the city of Nova Esperança (PR) from 1971 to 1997. Justified this period corresponds to the elaboration of laws that boosted the disciplinary field of art as well as its teaching. The empirical sources that bolstered the study were selected by means of official documents (laws, Reports, Minutes, Record Books for Teachers) and semi-structured interviews with former teachers and students. The analytical arguments emphasize the printing and the importance for school agents - teachers and students - the development and use of "Folders AZ". The final considerations highlight the problems with the filing of the sources for the development of educational research.

Keywords: Education, Brazilian Education History, Art Education, Teacher Training 
Neste artigo intencionamos demonstrar e analisar um formato de prática pedagógica que se desdobrou no cotidiano das salas de aula, do Curso Normal e Magistério, com o intuito de identificar e compreender como a disciplina de Educação Artística se organizou no período de 1971 a 1997. Período histórico correspondente à elaboração de Leis que impulsionaram o ensino da arte e a cessação do Curso Magistério. Há que se destacar que este artigo ampara-se em outro estudo, que se propôs a promover uma análise sobre a constituição da disciplina de Arte, ministrada no Curso Normal/Magistério, no interior do Colégio Estadual São Vicente de Paula, localizado na cidade de Nova

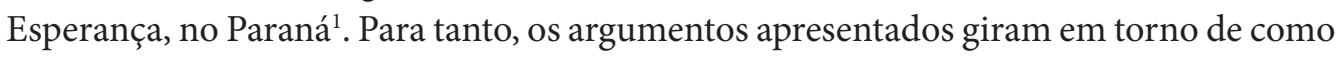
se constituiu o ensino de Educação Artística do Curso Normal Secundário e, posteriormente, Magistério, entre os anos de 1971 a 1997, focalizando questões que implicam a aproximação das práticas escolares com a formação de professores.

Ressaltamos, primeiramente, que a Federação de Arte-Educadores do Brasil - FAEB -, entidade representativa dos profissionais da Educação, do campo da Arte, solicitou, em 7 de abril de 1998, à Câmara de Educação Básica do Conselho Nacional de Educação, a retificação do termo "Educação Artística" para "Arte”, com base na formação específica plena, em uma das linguagens: Artes Visuais, Dança, Música e Teatro, no Inciso IV, Alínea b, do Artigo $3^{\circ}$, da Resolução CNE/CEB no 2, que instituiu as Diretrizes Curriculares Nacionais para o Ensino Fundamental. Esta Resolução foi aprovada em 04 de outubro de 2005, passando, assim, a constituir Arte como componente curricular obrigatório em qualquer nível de ensino da Educação Básica, promovendo o desenvolvimento cultural dos alunos, por não ser mais considerado um "simples fazer" e, sim, campo ou área de conhecimento (BRASIL, 2005).

Para os profissionais paranaenses, da rede pública de educação, o ensino no campo disciplinar da arte é mediado pelos objetivos da SEED² , desde 2008, propondo desenvolver nos alunos à aquisição de conhecimento em relação à "[...] diversidade de pensamento e de criação artística para expandir sua capacidade de criação e desenvolver o pensamento crítico" (PARANÁ, 2008, p. 52).

Considerando que o objetivo da Secretaria Estadual de Educação, referente ao campo disciplinar da Arte, nossa investigação centralizou-se na identificação dos conteúdos curriculares de Arte, focalizando e formulando problemas que implicam uma aproximação entre o ensino e as diferentes práticas escolares. Posto que, tal como Chervel (1990):

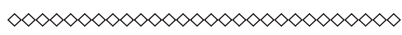

1 Esta temática foi amplamente desenvolvida, por Rosimara A. Mello, na dissertação de mestrado: CAMPO DISCIPLINAR E CULTURA ESCOLAR: A TRAJETÓRIA DO ENSINO DE ARTE NO CURSO NORMAL/ MAGISTÉRIO, NO COLÉGIO ESTADUAL SÃO VICENTE DE PAULA (NOVA ESPERANÇA, PR, 1971 - 1997), no Programa de Pós-Graduação em Educação da Universidade Estadual de Maringá, sob a orientação da Profa Dra Fátima Maria Neves.

2 Secretaria de Educação do Estado do Paraná. 
[...] descrição detalhada do ensino em cada uma das suas etapas, descrever a evolução da didática, pesquisar as razões da mudança, revelar a coerência interna dos diferentes procedimentos aos quais se apela, e estabelecer a ligação entre o ensino dispensado e as finalidades que presidem a seu exercício (CHERVEL,1990, p.192).

As Fontes ou o corpus empírico que amparam a investigação foram de diferentes abrangências. Selecionamos Leis e Documentos Oficiais, Atas Escolares, Livros de Presença e de conteúdos programáticos, fotografias, pastas de atividades, e entrevistas e depoimentos de professores e ex-alunos do curso Normal Secundário e Magistério, da Instituição em estudo. Compartilhamos do pressuposto de que a utilização de fontes empíricas tais como livros de registros, diários de classe, cadernos de planejamento, atividades e materiais pertencentes aos alunos e à escola, bem como entrevistas com professores e alunos ganham expressividade, uma vez que estes são considerados como um dos principais agentes da cultura escolar. Tais materiais revelam novos elementos desta cultura e ampliam o território da pesquisa. Entendemos que, ao explorar novos objetos de estudo e ampliando o rol de Fontes, o pesquisador tem a possibilidade de atribuir novos sentidos aos seus objetos, construindo outras representações, preservadas pela memória individual ou coletiva de uma época. Recorrer às fontes empíricas é, portanto,

[...] identificar no conjunto dos materiais produzidos por uma determinada época, por determinado grupo social, por determinada pessoa - homem ou mulher e segundo a etnia - aqueles que poderão dar sentido à pergunta que inicialmente se propôs; aqueles que, trabalhados, isto é, recortados e reagrupados, poderão servir de base à operação propriamente historiográfica, ou seja, à interpretação e à escrita (LOPES; GALVÃO, 2001, p.79).

A nosso ver, essas fontes representam: ideias e concepções de determinado grupo social e a história de determinada instância escolar, de determinado momento histórico, social e cultural. Instâncias que fornecem dados que compõem a cultura escolar e direcionam e conformam as disciplinas escolares.

Os dados coligidos, no rol de Fontes consultadas, revelam que, não obstante as diferenças políticas - do período de 1971 a 1997 -, o conjunto de conteúdos trabalhados nos registros de 1980 a 1985 tem muito em comum com os conteúdos descritos da década de 1970, principalmente os direcionados às técnicas artísticas e à construção do material didático, sucessivamente trabalhado em todas as turmas do Curso Magistério. Essa repetição de conteúdos é denominada por Chervel (1990) de "vulgata". Para o autor, as "vulgatas" se encontram em meio à farta documentação escolar, sendo que, "Em cada 
época, o ensino dispensado pelos professores é, grosso modo, idêntico, para a mesma disciplina e para o mesmo nível” (CHERVEL, 1990, p. 203).

A "vulgata" ainda se mantém, quando acontece o direcionamento dos conteúdos para os recursos audiovisuais implantados, em 1980, na grade curricular. Constatamos que a elaboração e a confecção dos materiais didáticos eram as mesmas utilizadas pelos professores nos anos 1970 e continuavam a ser ensinadas e confeccionadas, nas salas de aulas, década depois.

Observada as aproximações e as constâncias das práticas pedagógicas, emergem problemas de teor acadêmico, tais como: qual seria o objetivo de uma disciplina de "Recursos Áudio Visuais e Educação Artística"? Seria a construção de materiais para ilustrar e tornar concreto o ensino para a criança? Ou, haja vista as propostas e os cursos de formação que a SEED (Paraná, 1988) passou a ofertar nos fins dos anos oitenta, com o advento do videocassete (NEVES, 1997), instrumentalizar a prática pedagógica com o uso de equipamentos tecnológicos como retroprojetor, rádio, televisão, cinema?

O encaminhamento destas questões investigativas se revelou improdutivo diante da constatação, por meio das Entrevistas ${ }^{3}$, que os equipamentos disponíveis, no Colégio, eram: um retroprojetor, um gravador, um projetor de slides e duas "radiolas" portáteis. Embora, contassem com esses materiais disponíveis, pelo que consta, os professores não tinham o hábito de incluir em suas práticas pedagógicas tais recursos, mesmo que precários e insuficientes para atender à quantidade de salas de aula. Ressaltamos, inclusive, que o uso desses materiais não foi nenhuma vez citado nos registros e nos relatos das professoras. As fontes evidenciaram que os conteúdos e a dinâmica das aulas, em uma sociedade já midiática, ainda giravam em torno da confecção dos cartazes e das figuras referentes a determinado tema, por exemplo, "semana da alimentação" e as famosas "pastas A-Z".

As "Pastas A-Z" faziam parte de um projeto pedagógico de formação de professoras para o ensino de Arte. A elaboração e confecção das Pastas era realizada durante todo ano letivo, pelas alunas, sob a supervisão das professoras de Arte. As alunas compilavam atividades, desenvolvidas em sala de aula, na disciplina de Educação Artística, provenientes das técnicas de: pintura, colagem, dobradura, recorte, artesanato, enfim, tudo o que poderia ser arquivado, na Pasta. $\mathrm{O}$ objetivo era constituir um auxiliar pedagógico para posteriores usos, quando fossem atuar em sala de aula. A professora Amarelo ${ }^{4}$ descreve o emprego da pasta para aquele momento:

$\infty<\infty<\infty<\infty<\infty<\infty<\infty<\infty<\infty<\infty<\infty<\infty<$

3 Com Base nos Livros-Ata e nos Livros de Registro de Classe do Colégio Estadual São Vicente de Paula, convidamos para a entrevista quatro professoras e seis ex-alunas. Uma professora que lecionou na década de 1970, duas na década de 1980 (uma aposentada, outra atuando), e uma em exercício desde 1996. Entre as alunas entrevistadas; uma da década de 1970, três alunas da década de 1980 e duas da década de 1990. As entrevistas foram realizadas no período entre novembro de 2012 a fevereiro de 2013.

4 Para manter a privacidade das entrevistadas, utilizamos cores, para identificar as professoras. E, o nome de técnicas artísticas, para nomear as ex-alunas. 
"Sempre em cima do que elas iam trabalhar com os alunos no estágio, elas faziam muito estágio. Elas trabalhavam muito com a criança, não sei agora como que é, mais antes elas trabalhavam demais com as crianças. Era um suporte, era um material didático, um material didático. [...] Elas sempre usavam em cima do conteúdo que elas iriam trabalhar com as crianças depois no estágio delas e em sala de aula. [...] Era tudo feito em sala, a gente orientava e elas faziam" (PROFESSORA AMARELO,em exercício desde 1986).

As pastas eram encapadas pelas alunas que as personalizavam com muito capricho, dedicação ou obrigação, porque, no final do bimestre, seriam avaliadas e a apresentação do material fazia parte do conjunto de notas. Usavam tecidos e pintavam com tinta acrílica, encapavam com papel contact, com papel de presente ou estampado e plastificavam para maior durabilidade, sendo um dos objetivos da pasta o uso posterior em sala de aula.

As imagens das Figuras 1 a 3, a seguir, apresentam as pastas, destacando as capas e abertas, com exemplos de duas atividades:
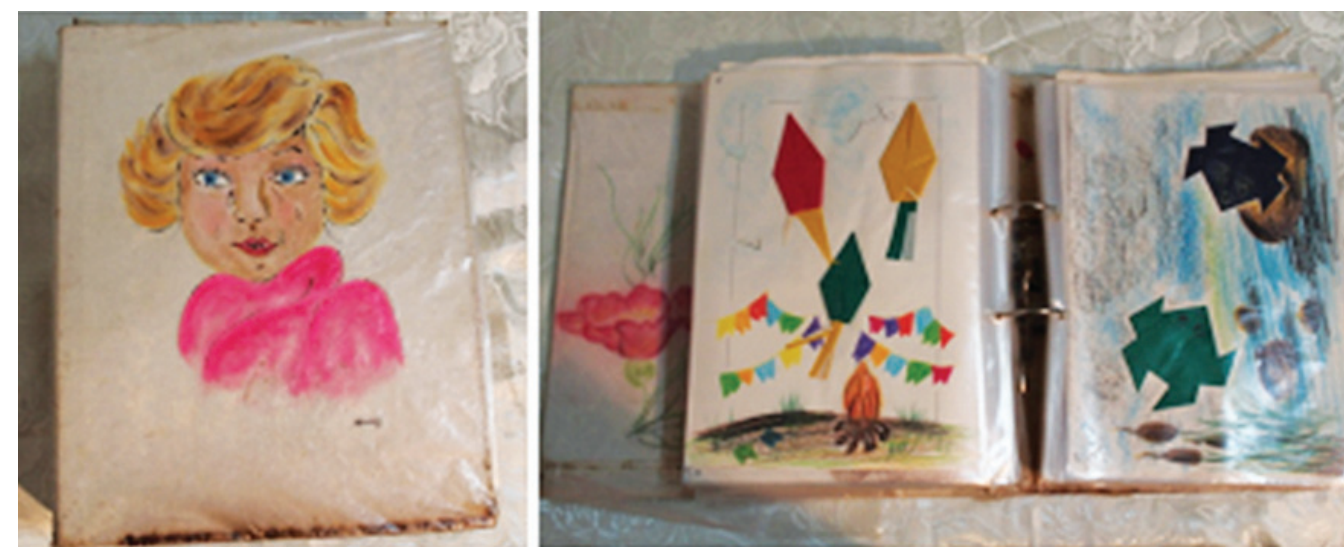

Figura 1: Pasta de ex-alunas do curso de Magistério de 1983, do Colégio Estadual São Vicente de Paula. Fonte: Arquivo pessoal da ex-aluna (1983-1985). 

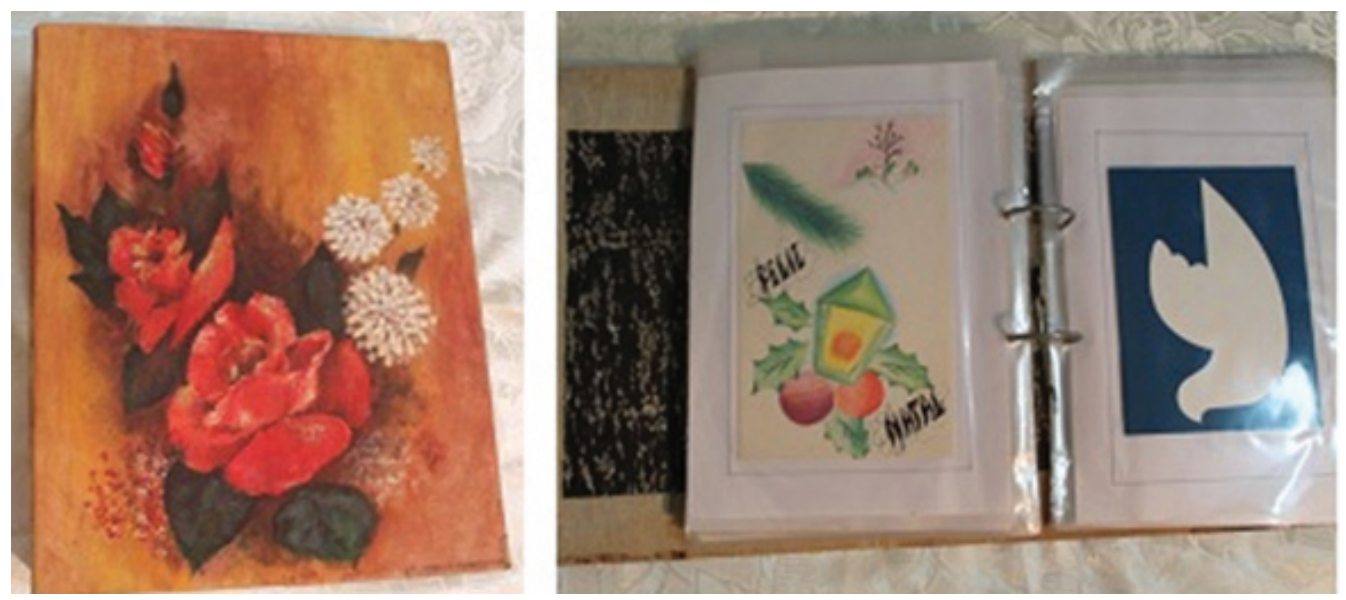

Figura 2: Pasta de ex-alunas do curso de Magistério da década de 1988, do Colégio Estadual São Vicente de Paula. Fonte: Arquivo pessoal da ex-aluna (1988-1990).
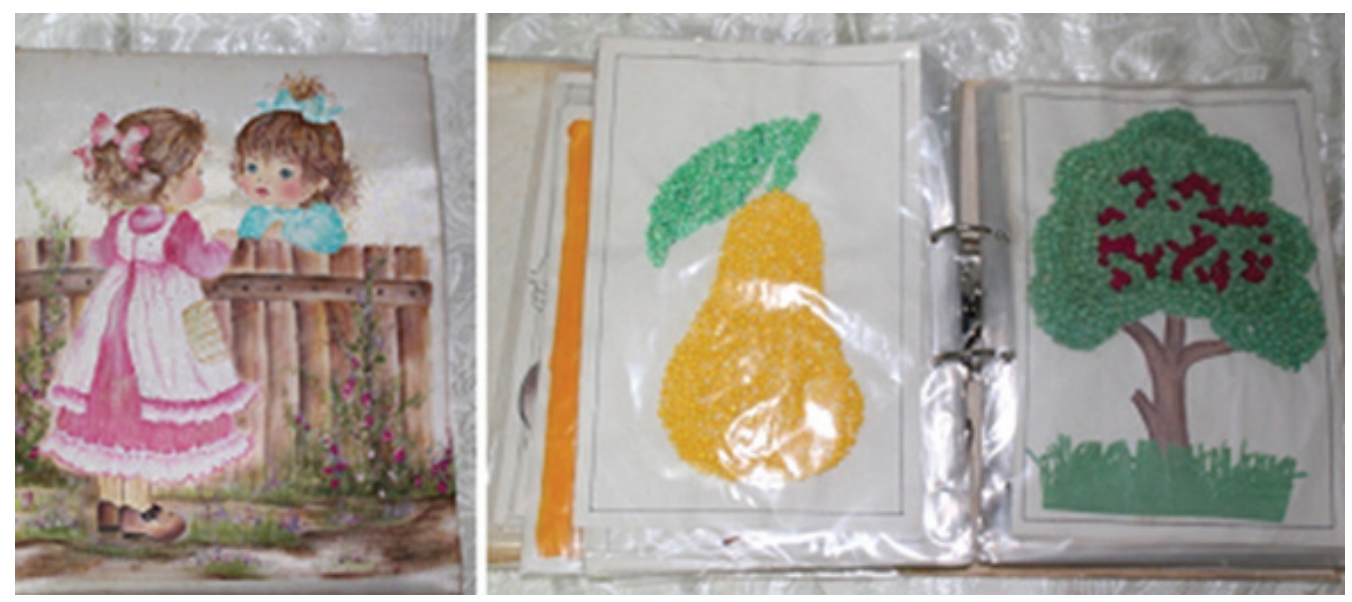

Figura 3: Pasta de ex-alunas do curso de Magistério da década de 1989, do Colégio Estadual São Vicente de Paula. Fonte: Arquivo pessoal da ex-aluna (1989-1991).

Essa "Pasta A-Z" foi, para professoras e alunas, um ícone da disciplina; toda dinâmica das aulas entre os anos de 1981 a 1990, giravam em torno da construção das atividades, e era considerada como uma grande responsabilidade. Por meio dos relatos de professoras e ex-alunas, observamos que todo planejamento e confecção da pasta eram disputados entre as alunas para a conquista da melhor, mais organizada, mais caprichosa e pasta mais criativa. Não passa despercebida a hierarquização social das alunas em uma mesma classe. Quanto mais condições financeiras a aluna tinha, mais materiais diversificados e nobres ela poderia empregar na aplicação das técnicas. Os depoimentos da professora Amarelo e da ex-aluna Crochê ressaltam: 
"[...] sempre tinha disputa nessas pastas também, sabia. Tinha disputa, porque (risos) uma queria ter mais bonita que a outra e queria cem, se fosse muito bonita era difícil você avaliar, sabe, mais sofisticado, mais chamativo era complicado também. Eu acho que era bem elitizada essa pasta se for analisar hoje, eu achava elas elitizada, porque eu sofria muito pra dar as notas, porque tinha aluna que eu dava uma nota boa e a outra que era... Que usou um material mais rico e é lógico ficou muito mais vistoso.[...] Assim, quanto mais poder aquisitivo a pessoa tinha, mais material diversificado, ela até comprava, sabe, pra ficar bem bonito, que nem você tem ali pra mostrar, era assim um material mais requintado, mais tinha aquele material bem simplezinho também, né, de tecido de retalhinhos, de botões" (PROFESSORA AMARELO, em exercício desde 1986).

A Ex-aluna completa a fala da professora:

\begin{abstract}
"[...] até mesmo tinha uma competição entre a gente, muito competição na construção da pasta, de fazer sabe aqueles exercícios. A gente competia muito, uma fazia assim a outra queria fazer um pouco melhor. Na verdade essa competitividade, ela trouxe assim, é, tirou a gente do senso comum, ah eu vou fazer qualquer trabalhinho e vou entregar, não era qualquer trabalhinho. [...] a Bel mandava a mãe dela fazer toda a pasta, por que era uma competição sabe,tinha que ser uma melhor que o outra" (EX-ALUNA CROCHÊ, 1989-1991).
\end{abstract}

No primeiro depoimento, percebemos a dificuldade em elencar critérios de avaliação, quando se tratava de atribuir notas aos trabalhos arquivados na pasta "A-Z". As alunas procuravam empregar os mais diversos materiais para a confecção de seus trabalhos, buscando harmonia e organização na aplicação da cada técnica. E, no segundo relato, notamos que as alunas procuravam superar o trabalho da colega, usando de vários recursos e ajuda, com o intuito de fazer o melhor trabalho.

Cada pasta confeccionada levava a singularidade do indivíduo que a produzira, por meio da escolha do tema da capa, do material utilizado para encapá-la - tecidos ou outros papéis -, das cores (umas suaves, outras fortes), do capricho e da dedicação.

Era um trabalho realizado durante todo o ano letivo; a cada técnica aprendida na aula, geralmente em papel sulfite, após o seu término, as atividades eram guardadas no plástico interno da pasta.

Os trabalhos eram separados por temas como: a) Técnicas de pinturas: do sombreamento, da pintura na camurça, da pintura com anilina, da pintura com tinta para tecido, da pintura do lápis de cor sobre a lixa, da pintura das máscaras de Páscoa, da pintura de cola colorida, da pintura com vela, do pontilhado em preto e do pontilhado 
colorido, do giz com leite, da pintura com lápis de olho, da pintura do dedo, sobre uma folha de revista, pintura com caneta de tinta seca e técnica da pintura com giz de cera e tinta nanquim.

Ilustraremos e delinearemos, a seguir, alguns exemplos das técnicas que compunham a pasta, com imagens dos trabalhos produzidos pelas alunas do curso de Magistério, da década de 1980, do Colégio Estadual São Vicente de Paula, reproduzidas nas Figuras de 4 a 6 :

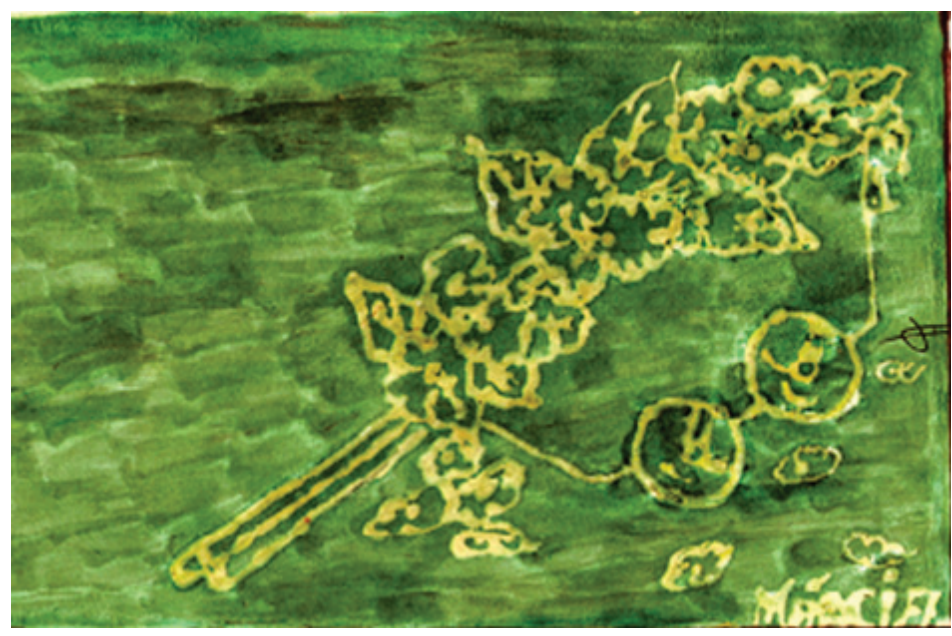

\section{Figura 4}

técnica da pintura com cola Fonte: Arquivo pessoal, ex-aluna, 10 Magistério, 1983, Colégio Estadual São Vicente de Paula.

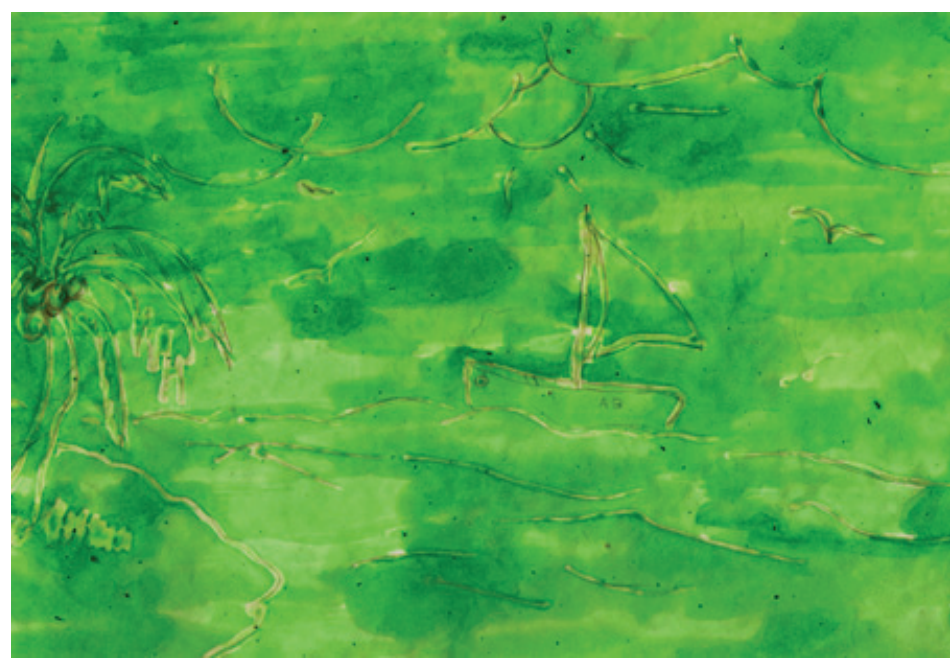

Figura 5

técnica da pintura com cola. Fonte: arquivo pessoal, ex-aluna, 10 Magistério, 1988, Colégio Estadual São Vicente de Paula. 


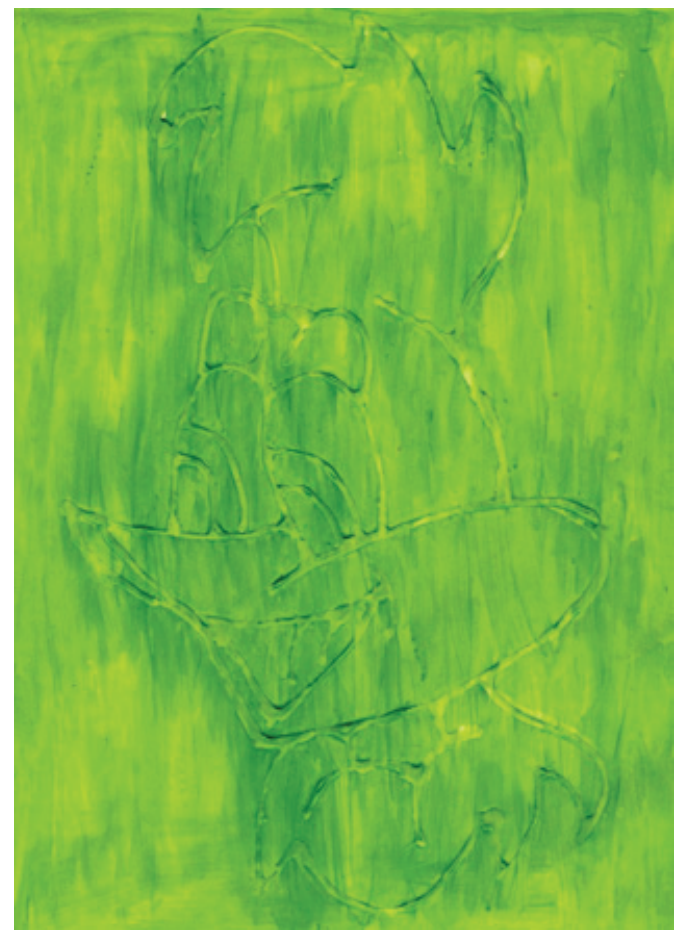

Figura 6

técnica da pintura com cola

Fonte: Arquivo pessoal, ex-aluna, 1 -

Magistério, 1989, Colégio Estadual

São Vicente de Paula.

A técnica de pintura com cola consiste em primeiro escolher um desenho e realizá-lo na superfície. No caso dos exemplos, as alunas utilizaram o sulfite, em que desenhavam bem de leve para que o grafite não ficasse marcado no papel. Após terminar o desenho, passa-se a cola branca por cima de todas as linhas e detalhes que se queira evidenciar, deixando secar bem. Depois de seca a cola, deve-se colorir com tinta bem líquida por toda a extensão da folha a fim de evidenciar, em relevo, as linhas contornadas com a cola que, após a secagem, ficarão transparentes.

Os desenhos escolhidos pelas alunas, nos anos letivos de 1983, 1988 e 1989, não apresentam, a nosso ver, inovações e originalidade, a técnica é mesma e, também o são as cores empregadas. O diferencial consiste na variação do modelo dos desenhos, alternando entre paisagens, objetos e personagem de desenho infantil e na tonalidade da cor, onde foram utilizados três matizes da cor verde.

b) Técnicas de colagem: da lantejoula, técnica da colagem do couro cru, da laise, técnica de colagem da pena branca e da pena colorida, da renda, técnica de colagem $\mathrm{cm}$ algodão, com miçangas, da linha ou barbante, do papel crepom, técnica de colagem do Bombril, com tecido de algodão, da casca de ovo, com o fio de lã e com a lã picada, do botão, do papel crepom enrolado, do papel rasgado, do papel laminado, sobre figura, com papel alumínio, do brocal, do pó de serra, da purpurina, do sagu, do palito de dente, técnica da colagem absurda, da madeira do lápis, da bolinha de isopor, de pó de chá, papel dobradura e do papel laminado picado e técnica da colagem de fundo. 
O exemplo seguinte (Figura 7) remete à técnica de colagem com barbante; muitas alunas anotavam, nos trabalhos, as datas comemorativas em que poderiam utilizá-los. Usavam a técnica da colagem do ovo, para representação do Dia da Ave ou a técnica da colagem com pena, para o trabalho do Dia do Índio e, desta maneira, utilizavam um vasto repertório de técnicas e materiais variados para a produção das atividades:

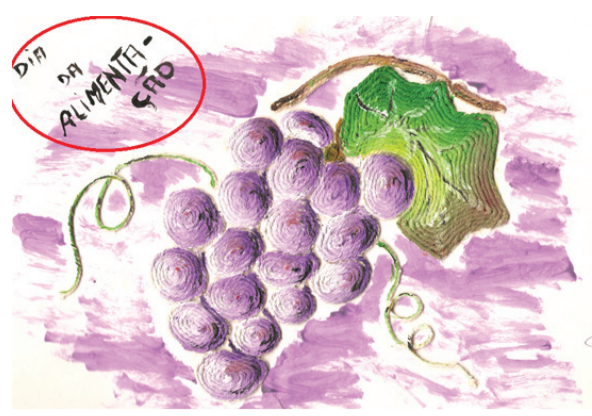

\section{Figura 7}

técnica de colagem com barbante Fonte: Arquivo pessoal, ex-aluna, 1ำ Magistério, 1983, Colégio Estadual São Vicente de Paula.

c) Bordados e botões: técnica de pregar diferentes tipos de botões (botões com dois furos, quatros furos e estilo pérola), ponto correntinha, ponto cheio, ponto atrás, ponto cruz e ponto alinhavo. A Figura 8 a seguir é um exemplo do ponto correntinha, arquivado na pasta de 1989 e a Figura 9 exemplos de botões arquivados na pasta de 1988.

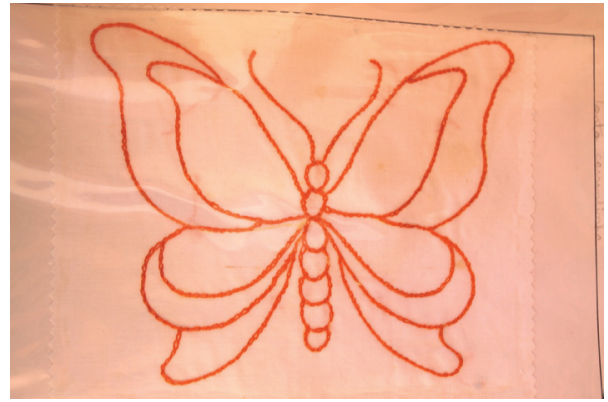

Figura 8

Ponto correntinha

Fonte: Arquivo pessoal, ex-aluna, 1ㅇ Magistério, 1989, Colégio Estadual São Vicente de Paula.

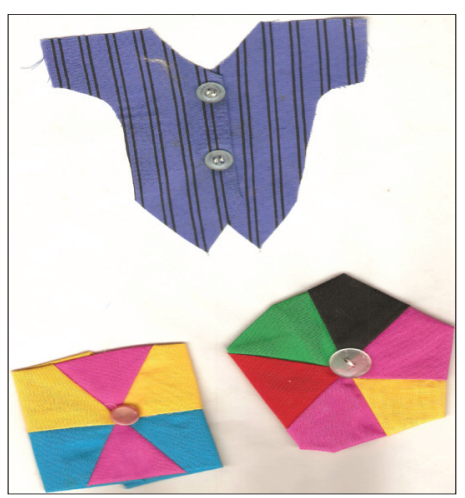

Figura 9

Pregar botões de quatro furos, dois furos e estilo pérola.

Fonte: arquivo pessoal, ex-aluna, 1ㅇMagistério, 1988, Colégio Estadual São Vicente de Paula. 
d) Tricô: ponto tricô, ponto barra e ponto arroz, conforme mostra a Figura 10.

e) Crochê: caseado, ponto alto, ponto baixo, amostras de bicos, de toalhinhas e caminhos, a Figura 11 reproduz o resultado desta técnica:

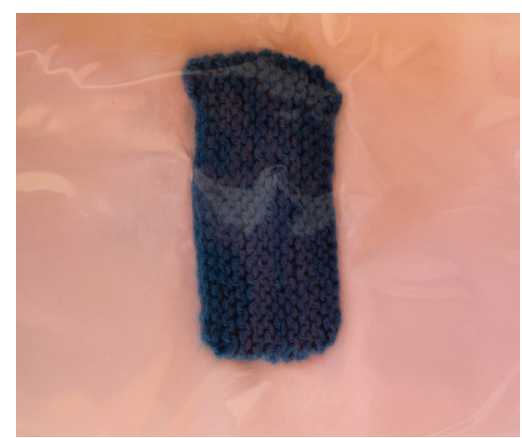

Figura 10

Ponto do tricô

Fonte: Arquivo pessoal, ex-aluna, 1ำ Magistério, 1989, Colégio Estadual São Vicente de Paula.

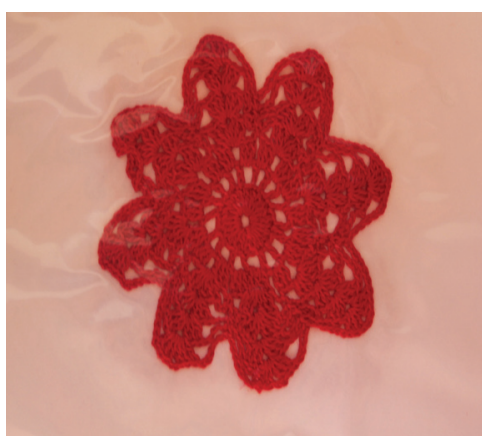

\section{Figura 11}

Amostra de toalhinha de crochê

Fonte: Arquivo pessoal, ex-aluna, 10 Magistério, 1989, Colégio Estadual São Vicente de Paula.

f) Cartões: cartões para Dia das Mães, de aniversário com temas variados para meninas e para meninos, para o Dia dos Professores, para o Dia dos Pais e cartões para o Natal. As Figuras 12 e 13 mostram os tipos de cartões:

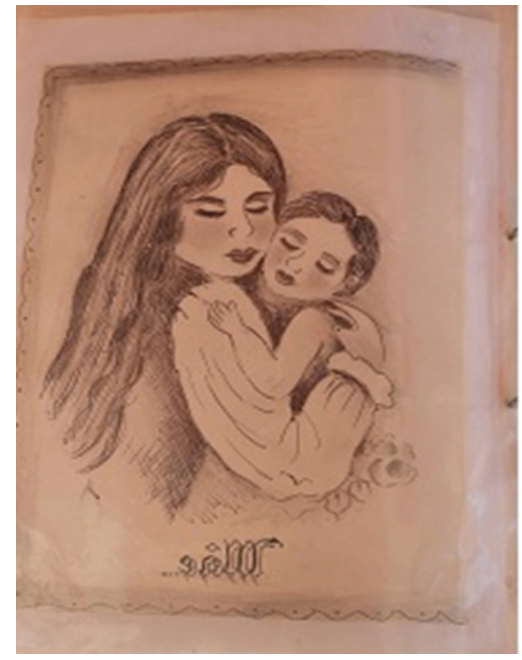

\section{Figura 12}

Cartão para o Dia das Mães

Fonte: Arquivo pessoal, ex-aluna, 1을 Magistério, 1989, Colégio Estadual São Vicente de Paula

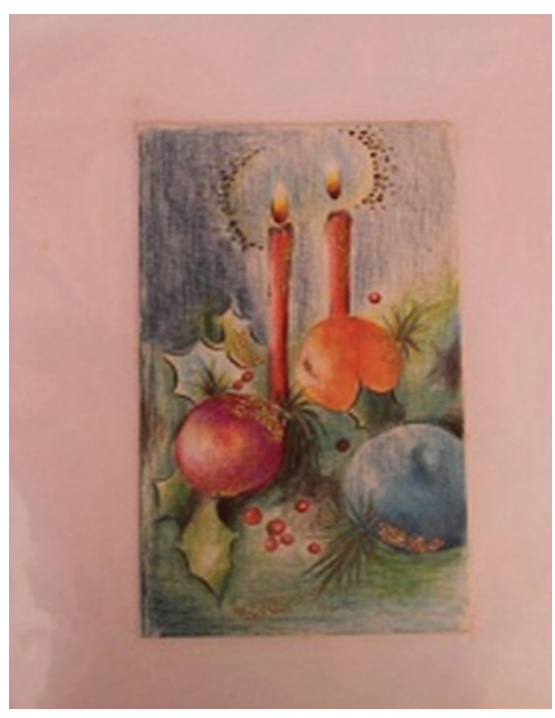

Figura 13

Cartão para o Natal

Fonte: Arquivo pessoal, ex-aluna, 1ำ Magistério, 1989, Colégio Estadual São Vicente de Paula 
g) Dobraduras: dobraduras de gatos, corações, galinha, cachorro, coelho, foguete, bandeirinha, casinha, tulipa e pássaro, conforme demonstram as Figuras 14 e 15:

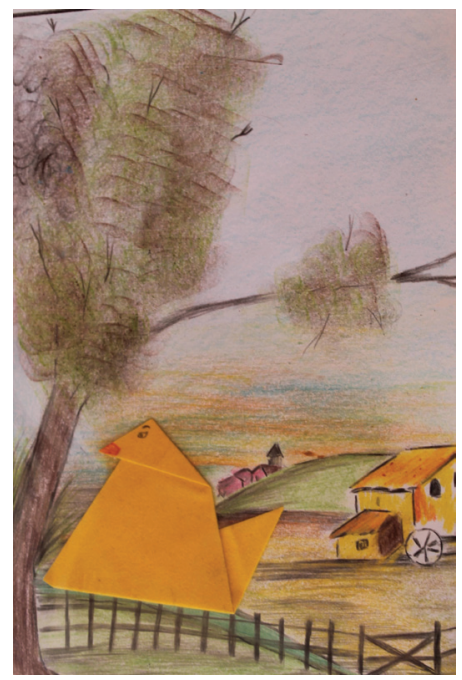

Figura 14

Dobradura de galinha

Fonte: Arquivo pessoal, ex-aluna, 1을 Magistério,

1983, Colégio Estadual São Vicente de Paula

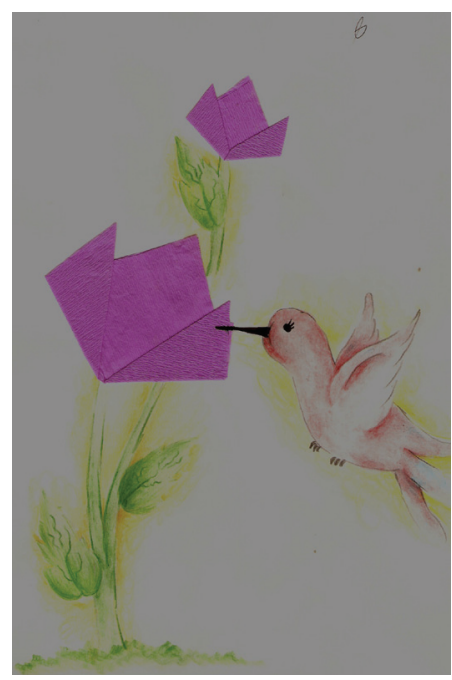

Figura 15

Dobradura de tulipa

Fonte: arquivo pessoal, ex-aluna, 4을agistério, 1994, Colégio Estadual São Vicente de Paula

Nos chama à atenção, as atividades de dobraduras eram conduzidas para fazer parte de uma composição como os exemplos da dobradura da galinha, que completa o cenário rural, e a dobradura de tulipa, juntamente com o desenho do beija-flor. Tais temas eram orientados pela professora no início de cada aula ou do bimestre e o trabalho executado pelas alunas, assim como destacado nos relatos a seguir:

"A professora passava o que nós íamos fazer durante aquele bimestre, e cada um ia montado a sua pasta com plástico, ia montando no sulfite..." (EX-ALUNA PINTURA,1980 a 1982 ).

"Tinha uma pasta que a gente montava todas as atividades, que era aquela pasta de capa preta com plástico, montava tudo ali. Ela dava, vistava todo bimestre. Era tudo arquivado em pasta" (ALUNA TRICÔ, 1983 a 1985).

"Primeiro, ela colocava a proposta do que ela iria ensinar, o objetivo daquilo e aí ela detalhava passo a passo e aí, na própria aula, a gente 
produzia, às vezes não dava tempo de terminar a atividade na mesma aula, né, daí a gente terminava em casa e trazia pronta já dentro da pasta pra ser avaliada. Aí no final do bimestre era avaliado os trabalhos que foram feitos durante aquele bimestre" (ALUNA CROCHÊ, 1989 a 1991).

Nas aulas de Educação Artística, do Magistério, durante os anos de 1981 a 1990, a aprendizagem, portanto, compreendia os desenhos para pintar e colar, o crochê, o tricô, o bordado, o pregar botões, os cartões de aniversários, presentes nas pastas, até as confecções dos cartazes e figuras, correspondendo ao auge de uma noção de ensino de Arte atrelado aos conteúdos reprodutivistas, mais que cumpria uma finalidade. A professora Amarelo aponta um dos objetivos dessas atividades:

\begin{abstract}
"Tem que trabalhar alguma coisa pra depois criar. Então se elas levavam o desenho o desenho mimeografado pra, pras crianças, eu me lembro, sabe. Lá tinha uma data comemorativa se elas iam trabalhar, essa data elas levavam sim pras crianças, mais elas trabalhavam todo o conteúdo, explicava tudo aquilo. Eu me lembro, que sempre tinha poema elas liam, naquela época a menina que fazia magistério, ela lia muito pras crianças que ela fosse estagiar, sabe. Lembro que tinha sempre que lê historinha, sempre tinha que fazer essa parte oral, essa oralidade, né? E elas levavam desenhinhos prontos sim, aí eles pintavam porque depois elas traziam pra gente vê, sabe, o desenhinho que os alunos pintavam. E tudo era válido, só de você contornar o desenho você tá trabalhando coordenação. Porque hoje a criança vai no Pré, mais antes a criança não ia, nem todas iam no Pré, era outra realida$d e "$ (PROFESSORA AMARELO, desde 1986).
\end{abstract}

$\mathrm{Na}$ atualidade, amparadas em uma visão contemporânea de ensino e de aprendizagem, nos distanciamos sobremaneira das posturas apresentadas. Todavia, entendemos que, tanto alunos como professores procuravam desempenhar suas funções da melhor maneira possível. Acreditavam em uma proposta de ensino e se dedicavam a ela. A aluna Crochê descreve, com segurança, sua formação:

"O que nós aprendemos no Magistério era você levar o conteúdo, era levar a criança a desenvolver aquelas atividade que você previamente planejou, né. [...] Muitas coisas que nós vivenciamos nas aulas e no decorrer do curso, foi o que nós levamos para o nosso início de experiência profissional, início da nossa carreira, né. E, assim, a gente via a diferença do professor que fazia magistério e recebido toda essa aula de Arte e de outras disciplinas como Didática, do professor que não ti- 
nha feito o magistério. [...] Na nossa época, também era assim, a gente também passava desenhos prontos, vamos dizer assim, só que lógico tinha um objetivo, tava tudo ali planejado. Então, essa organização de planejamento, de datas comemorativas, de por que desenvolver tal atividade, o que eu quero com isso, lógico que foi através das aulas do magistério e das aulas de Artes" (ALUNA CROCHÊ, 1989-1991).

Ao construir a pasta, as alunas reproduziam, ano a ano, os desenhos umas das outras, ou faziam cópias dos "Álbuns de Motivos Artísticos Educacionais oferecidos pelas editoras e seus revendedores que visitavam as escolas da cidade, para vender esse material. Tais manuais, afirmavam os vendedores, proporcionavam um material didático "[...] indispensável na preparação de um plano de aula eficiente, na execução de deveres didáticos e artísticos na escola e na confecção de painéis, capas de provas, comemorações, enfeites em sala de aulas, etc." (SALAS, 1973, p. 01). A circulação dessas coleções contribuiu e muito para o apoio tanto dos professores como das alunas do Magistério na organização e produção das atividades de Educação Artística:

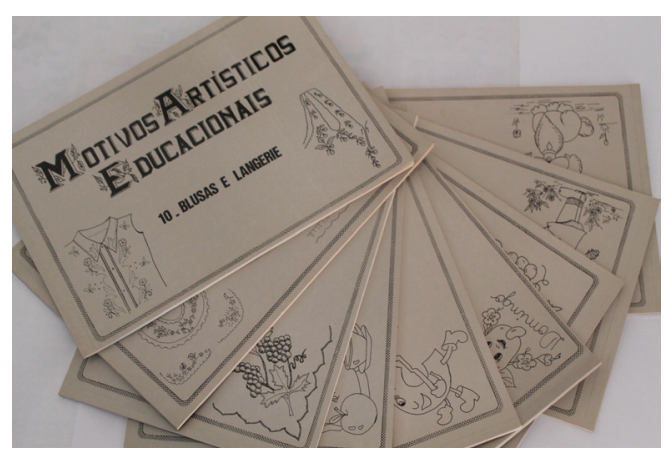

\section{Figura 16}

Coleção dos álbuns de “Motivos Artísticos e Educacionais, 1973.

Fonte: Arquivo pessoal da autora.

A pasta, com toda sua construção, a partir do ano de 1991, deixou de ser a protagonista das aulas, e grande parte das técnicas eram produzidas pelos alunos como trabalho domiciliar, na disciplina de Fundamentos da Educação Pré-Escolar, conforme relato da aluna entrevistada:

"Cada aluna tinha uma pasta. Em cada bimestre a professora determinava quais seriam as técnicas que seriam confeccionadas e posteriormente avaliadas. Não me lembro de fazer em sala de aula, em sala de aula ela explicava como deveria ser feita cada técnica e fazíamos em casa. Como tinha uma irmã que já havia feito o magistério eu já tinha ideias da importância daquelas pastas e procurava fazer coisas diferentes das feitas pela minha irmã. A professora N. era muito exigente e no dia da avaliação todas as alunas ficavam muito nervosas e apreensivas. Quando ela chamava para irmos até sua mesa com a 
pasta A Z, ficamos olhando sua expressão de aprovação ou não. Sempre valorizei muito a confecção dos trabalhos, sempre foi muito importante pra mim" (ALUNA DESENHO, 1991-1994).

Por meio do depoimento da ex-aluna, percebe-se que a pasta era um trabalho muito valorizado no Curso e essa estima era transferida por gerações entre as alunas, que tomavam como referência a pasta uma das outras. A descrição de como era realizada a confecção das pastas pela aluna Pintura, pouco difere dos anos em que as mesmas eram produzidas na disciplina de Educação Artística. Desta maneira, comprovamos a importância das referidas pastas para o Curso Magistério.

A produção das pastas na aula de Educação Artística, foi uma alteração proveniente da nova organização curricular, do ano de 1991. A disciplina de Educação Artística é oferecida, neste momento (1991), apenas em uma turma, na primeira série, com uma única aula; e no ano de 1994 o curso passa novamente por mais uma alteração da estrutura curricular alicerçada na "[...] Deliberação n.o 002/90 e Parecer n. ${ }^{\circ}$ 001/90, constituindo-se desta forma as novas Diretrizes Curriculares da Habilitação Magistério para o Estado do Paraná" (ALMEIDA, 2004, p. 56).

Com a nova matriz curricular, as aulas na disciplina de Educação Artística foram reduzidas, as disciplinas de Metodologia foram acrescentadas, e as práticas da construção dessas pastas permaneceram, sendo trabalhadas nas disciplinas específicas do curso. Ao mesmo tempo em que a disciplina, ao longo de sua história veio se constituindo como componente curricular obrigatório, o número de aula foi diminuindo.

Quanto às produções das pastas, nas disciplinas de Metodologia, as técnicas e a organização dos trabalhos seguiam o mesmo padrão da década de 1980, com a apresentação das técnicas de pintura, técnicas de colagem, cartões, bordados e dobraduras. Após o término do projeto das pastas nas aulas de Educação Artísticas, algumas técnicas eram trabalhadas, esporadicamente, em datas comemorativas ou interrompia uma sequência de registros do trabalho com a História da Arte.

Dessa maneira, as técnicas artísticas e formato prosseguiram da mesma maneira dando continuidade à cultura de ensino criada pelo Magistério do Colégio Estadual São Vicente de Paula, em Nova Esperança, tal como era feita em anos e matrizes curriculares anteriores, como demonstra a imagem, de uma Pasta elaborada em 1993 (Figura 17):
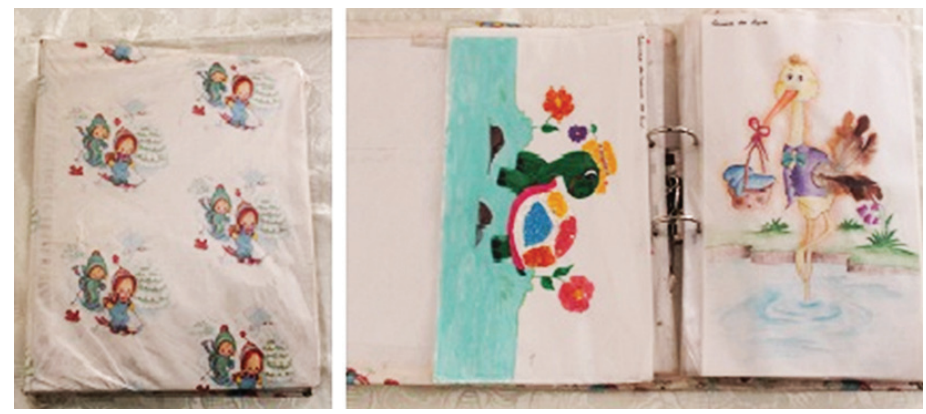

Figura 17

Pasta de ex-alunas do curso magistério do ano de 1993, do Colégio Estadual São Vicente de Paula Fonte: Arquivo pessoal da ex-aluna 
As aulas semanais de Educação Artística, conforme os conteúdos apresentados nos Livros de Registro, passaram da produção das pastas, aos estudos da Linha do Tempo da História da Arte. O conteúdo abordado nas aulas compreendia os periodos consagrados pela historiografia tradicional, a saber: Pré-história, Arte Mesopotâmica, Arte Egípcia, Arte Grega e Romana, Arte na Idade Média (com estudos dos estilos Gótico, Bizantinos e Romanicos), Arte Renascentista, Arte Barroca, Impressionismo, Expressionismo, Cubismo, Dadaismo, Surrealismo, Futurismo até a Arte Moderna.

A professora Amarelo, em seu depoimento, contempla essa mudança que, a nosso ver, marca uma transição de metodologia, deixando, naquele momento, nas aulas de Educação Artística, os professores envolvidos desorientados e confusos, por não terem ou receberem um encaminhamento metológico:

\begin{abstract}
"Teve uma mudança também porque era só pasta, só pasta e depois deu uma mudadinha, começou, assim se preocupar mais com História da Arte, né, aí eu peguei essa parte também. [...] eu acho que depois veio História da Arte no magistério, mais eu não me lembro de ter trabalhado isso. Deixa eu ver se tem alguma coisa aqui pra eu ver" (olhando os livros de registro) (PROFESSORA AMARELO, em exercício desde 1986).
\end{abstract}

A dúvida ou o esquecimento da Professora Amarelo em relação ao conteúdo de História da Arte, fazendo com que ela procure evidencias em suas anotações no Livro de Registro de Classe, da época em que lecionou, nos remete a um outro dado que surgiu na investigação. Quando entramos em contato com as ex-alunas do curso Magistério nos anos de 1991 a 1997, para a entrevista, as mesmas não se lembravam das aulas de Educação Artística, da professora que lecionou a disciplina e de nenhum conteúdo ou atividade que realizaram na referida disciplina.

Com a mudança do conteúdo programático (da elaboração das pastas para a história dos movimentos artísticos), as aulas de Educação Artística receberam um novo direcionamento; os cadernos de Arte substituíram as pastas e os aspectos mais históricos e teóricos tomaram o lugar das técnicas artísticas. A Professora Roxo descreve a dinâmica das suas aulas:

\footnotetext{
"Na época, não era um pasta, era um caderno de Arte mesmo. Nesse Caderno de Arte, elas escreviam tanto a teoria como os desenhos relacionados ao movimento histórico que tava sendo é, colocado. E como era um ano só que tinha Arte, tinha que passar por toda a história da arte com elas naquele ano, com uma aula por semana. Então, tinha que ser muito corrido, você tinha que explicar qual era o objetivo da, na Pré-história. Não dava tempo de trabalhar a música, teatro e nem
} 
pensar em dança. Imagine uma aula por semana, passava voando e por passar por todo o conteúdo da história da Arte, era bem difícil" (PROFESSORA ROXA, em exercício desde 1996).

Com o novo formato metodológico, vieram os obstáculos a serem enfrentando pelos professores como, por exemplo, a carência de material didático para apoio em sala de aula, entre eles, livros de História da Arte e as imagens de obras de Arte e a cobrança em se adequar ao novo sistema.

Constatamos que ao serem trabalhados os conteúdos de História da Arte, semanalmente, seguindo o formato relatado pela professora, as aulas se "esvaziaram" de significado e de aprendizagem para as alunas, diferentemente do que acontecia com as aulas que trabalhavam as técnicas e construção das pastas que girava em torno da vivência e hábitos das salas de aulas do município.

A cultura escolar criada durante os anos no interior do curso projetava nas mesmas, a expectativa de atividades práticas que as preparariam para a ação docente. No entanto, deparar-se com um conteúdo teórico que deveria proporcionar o desenvolvimento sensível, a ampliação do repertório artístico, estético, o contato com os movimentos artístico e seus expoentes também causou estranheza entre as alunas. Acostumadas à realização de tarefas técnicas e a muito trabalho artístico, as alunas criavam, algo que pode ser entendido como "repulsa" à nova dinâmica proposta para as aulas de Educação Artística. Esse "desprestígio" é abordado pela Professora Roxo:

"Olha os alunos, eles não tinham, não davam muito valor. Porque eles achavam que justamente a Arte era pra isso, que era pra embelezar, né. Tinham a Arte só como estética, não como é [...], é a vivência de uma sociedade, eles não tinham a Arte como história, a história humana, a história sensível de uma sociedade, o sentimento mesmo da sociedade. [...] Então, elas não davam valor e a partir do momento em que você explicava o porquê daquilo alí, porque o homem faziam aquilo, de onde tudo começou, porque ele começou dessa forma. Então, você explicando cada movimento artístico, trazendo pra um significado humano, ou seja, existiu porque foi o ser humano que fez, porque tá marcando uma transição dessa sociedade nessa época. Aí, então, elas começavam a ter, assim, uma vontade de conhecer mais, se não elas não queriam. Queriam só pintar, recortar colar, a vamos fazer um desenhinho bonitinho, professora, por que você não passa um. Eles queriam ainda folhinha pronta pra eles pintar, ah! Professora, você não passou nada prontinho pra gente recortar e passar pros nossos aluninhos. [...] elas começavam a se interessar e aí elas começaram a ver a Arte com outros olhos" (PROFESSORA ROXO, desde 1996). (Grifo nosso) 
Entendemos que o procedimento em relacionar o conteúdo programático com o contexto social e cultural criou uma sintonia diferente em sala de aula. Criou uma forma de "ver a Arte com outros olhos", que neste caso, foi o de se apropriar do conhecimento, de um conteúdo ou de uma história que começou a ser significativa para as alunas. A nosso ver, entendemos que, a partir do momento em que o aluno tem a possibilidade e a compreensão do significado do processo histórico, estético e cultural, destinado ao campo da Arte, ele passará a entender o processo histórico e com suas nuances e a vivenciar novas experiência em arte. $\mathrm{O}$ desconhecido, inicialmente, causa estranhamento, não só para as professoras, também para os alunos; cada um agindo de determinada maneira, procura expressar seu sentimento de descontentamento com o que está envolvido. Desta maneira, o "ver a arte com outros olhos" corresponde à adequação de novos conteúdos, novas posturas, novos hábitos e um longo caminho a ser percorrido por parte da comunidade escolar e fora dela, criando, assim, uma nova cultura para a disciplina.

As fontes indicam-nos que tanto os conteúdos ensinados em Educação Artística, como o trabalho do professor se tornaram pormenorizado. De um lado, o professor, desamparado, tentando se adequar a um novo sistema de ensino, sem material, sem formação continuada e com apenas uma aula semanal. E, de outro, o aluno recebendo fragmentos de um conteúdo superficial. Portanto, recorremos às palavras da professora Roxo, "era o que dava pra fazer", sendo assim, essas aulas não foram guardadas como lembranças afetivas e significativas pelas respectivas alunas:

\footnotetext{
"Eu lembro do Magistério e do Colégio com muito carinho e com muita saudade. A minha formação no magistério foi a base e o início da minha formação enquanto psicóloga, professora e pessoa. Aprendi muito durante as aulas de didática, sociologia, filosofia, com as feiras de ciências, com saraus que organizamos e com as apresentações durante o ano letivo, mas não me lembro infelizmente das aulas de Educação Artística. Talvez por terem sido poucas e não tão intensas e significativas para minha formação como as demais disciplinas" (ALUNA DESENHO, 1991-1994).
}

Identificamos, no relato da aluna Desenho, que os conteúdos apresentados nos Livros de Registro de Classe, durante sua formação na década de 1990, como mencionamos anteriormente, não estabeleceram uma relação afetiva com o processo de aprendizagem. Compreendemos, assim, que embora a disciplina nas décadas anteriores (1970 e 1980) não trabalhasse os conteúdos diretamente direcionados ao conhecimento teórico das linguagens artísticas e a História da Arte, as alunas recordam-se das aulas, da professora e das atividades que realizaram; além de mencionarem as contribuições que a disciplina de Educação Artística proporcionou para o futuro trabalho para ser desenvolvido em sala de aula. Diferentemente da experiência e vivência das alunas da década de 
1990, cujas alunas além de não ter nenhuma recordação das aulas de Educação Artística relatam a falta de significação à formação pessoal e profissional.

Nessas circunstâncias, as alunas do curso Magistério da década de 1990, considerando seus depoimentos, não tiveram a possibilidade de uma aprendizagem significativa (no sentido de prática) que desenvolvesse a expressão artística e criadora, a criatividade, o olhar estético, sensível e reflexivo, entre outras potencialidades fundamentais que a disciplina proporciona à formação do professor da Educação Infantil e Séries Iniciais. Para tanto, a carga horária da disciplina deveria ser maior e dispor de uma proposta sistematizada para mudar ou alterar este estado de "insignificância", analisando:

[...] De um lado o seu papel na formação da percepção e da sensibilidade do aluno através do trabalho criador, da apropriação do conhecimento artístico e do contato com a produção cultural existente. E, de outro lado, colher a significação da arte no processo de humanização do homem, visto que este, como ser criador, se transforma e transforma a natureza através do trabalho, produzindo assim, novas maneiras de ver e sentir. (PARANÁ, 2003, p. 126).

O desenvolvimento da sensibilidade, do ver, do sentir, do refletir e do conhecimento artístico, dialogando com o plano da subjetividade, tem um papel fundamental na formação das alunas no Curso Magistério. Esta afirmação pode ser observada no construto teórico de especialistas em arte. Stabile (1989) pontua que a formação do professor da Educação Infantil deve incluir o conhecimento da evolução gráfica da criança, para planejar adequadamente as atividades de autoexpressão, além de criar situações que estimulem a capacidade criadora, utilizando dos recursos artísticos valiosos para o desenvolvimento dos alunos. Yolanda (1967, p. 21) ressalta que cabe ao professor da Educação Infantil e séries iniciais, "[...] ser ele próprio um criador no desempenho de sua tarefa, permitindo aos alunos, igualmente, liberar sua potencialidade criadora”. Martins \& Guerra (1998), por sua vez, destacam que o educador precisa manter a diligência no estudo e pesquisa, para instigar seus alunos com ideias germinadoras, dispor de imagens visuais, sonoras, cênicas, desafiando o educando a ousar e buscando novas perspectivas ao ver, ouvir e agir de maneira pessoal e coletiva.

Contudo, observamos que, o último ano em que a disciplina de Educação Artística foi ministrada no curso Magistério, do Colégio pesquisado, foi em 1997; e o encerramento do curso, no ano de 1999, os conteúdos ensinados seguiam os mesmos caminhos, configurados do estudo cronológico da arte Pré-histórica a arte Moderna,

Objetivando delinear novas finalidades significativas aos alunos, os professores procuravam, em suas aulas, explicar os movimentos artísticos, relacionado-os a um significado histórico e expressivo; totalmente diferente do trabalho da disciplina dos anos anteriores. Desta maneira, os mesmos perceberam que levariam um tempo para que os 
alunos tomassem consciência do novo direcionamento que a disciplina tinha tomando. Para os professores, aquele momento era para fazer com que os alunos desenvolvessem o gosto por aprender arte, o conhecimento das linguagens específicas da arte e, acima de tudo, o que o ser humano pode expressar por meio dela. A continuidade da pesquisa nos permitira construir problematizações sobre as concepções de arte vigente entre esses novos profissionais.

\section{Consideraç̧ões finais}

Dentre os muitos argumentos que poderiam figurar nas considerações finais, aqueles que fazem parte da fase de identificação e seleção das Fontes ganham, inicialmente, prioridade. Presenciamos a visível falta de estrutura e organização escolar em arquivar documentos que são o retrato do cotidiano da escola de determinado momento histórico, como ressalta Silva (2010), quando discorre sobre a falta de políticas públicas direcionadas à preservação e conservação da história e do patrimônio escolar. O descaso com a produção material escolar - tornadas fontes - pode indicar uma cultura de desvalorização da memória escolar brasileira ou a falta de "cultura, consciência e experiência" em perceber os registros como fontes relevantes para a pesquisa científica. Produção que poderia ser entendida como material empírico importante e relevante para a compreensão dos fenômenos que compõem o campo do ensino e da pesquisa em História da Educação no Brasil. Constituindo assim, um campo de memória social coletiva.

Para Le Goff (2003, p. 419), a memória é um conjunto de funções psíquicas, como uma propriedade de preservar informações que o homem utiliza para representação do passado. Segundo o autor, essas memórias individuais são selecionadas, quer a respeito das recordações, quer a propósito do esquecimento, e vão sendo manipuladas, consciente ou inconscientemente, pelo interesse particular atribuído a elas. Também podemos nos remeter à memória coletiva da mesma maneira, quando nos reportamos a assuntos que foram marcados para ser lembrados pela população, por classe dominante, ou documentos que foram selecionados para permanecer na escola, representando o vivido. Neste sentido, os "[...] esquecimentos e os silêncios da história são reveladores destes mecanismos de manipulação da memória coletiva [...]" (LE GOFF, 2003, p. 422), e a escola e tudo que nela há é palco de vestígios de lembranças que podem esclarecer dúvidas da História da Educação.

Exemplos de documentos para permanecerem na escola por escolha são regulamentados pela Deliberação no 031/86, aprovada em 05 de dezembro de 1986, no processo no 362/85, pelo Conselho Estadual de Educação, do Estado do Paraná. Tendo em vista o Parecer $n^{\circ} 00 / 86^{5}$, constam cinco artigos (Art. 2, 3, 4, 5, 6) sobre incineração de

$\infty<\infty<\infty<\infty<\infty<\infty<\infty<\infty<\infty<\infty<\infty<\infty<$

5 Relatório do Parecer no 004/86, em anexo à Deliberação n. 031/86 - 1986. Disponível em: http://www.nre.seed.pr.gov.br/paranavai/arquivos/File/Del_3186_Incineracao_Doc.pdf. 
documentos escolares e documentos escolares com prazo para transferência.

A Deliberação, além de deixar para a direção do estabelecimento de ensino a responsabilidade de selecionar qual documento será ou não de relevância para ser descartado, prevê que tais documentos devem ser registrados em atas, com nome dos alunos, ano letivo, série ou período em que estudaram, o grau de ensino, bem como todos os dados referentes à identificação do documento eliminado pela incineração. Estas anotações resultam, também, em acúmulo de papéis ou ocupação de funcionários, que, na escola de rede pública, encontram-se escassas para execução de mais este trabalho.

Contudo, a legislação deixa clara a preocupação dos administradores escolares com a falta de espaço físico para o arquivamento de documentos, com o grande crescimento do alunado ano a ano. O Estado, como mantenedor, repassa, mais uma vez, a responsabilidade da organização de todo o arquivo produzido no estabelecimento de ensino, assim como da acomodação dos alunos nas salas de aula, para o corpo administrativo da escola. Lembremos que essa Deliberação continua em vigor até a data desta pesquisa, 2013, no Estado do Paraná.

A recriação e a ressignificação desses documentos são mais complexas do que imaginamos, visto que dependem não só do pesquisador, mas também dos arquivos, acervos, imagens, diários, registros, objetos e de outros que estiverem à disposição do pesquisador, para tomá-los como fontes.

Finalizamos nossas considerações, destacando que as "Pastas A-Z", objeto de estudo, deste artigo, constituiu em uma metodologia e um material didático criada pelos professores, pela escola, pelo curso e para o curso. Essas pastas estabeleceram uma relação afetiva e significativa para a aprendizagem dos alunos, do recorte pesquisado. Visto que, durante a realização das técnicas e o emprego das mesmas nas escolas, os alunos e professores procuravam objetivos e finalidades didáticas para transformar o ensino em aprendizagem. Além disso, segundo relato das alunas, as lembranças que, ainda hoje, o material proporciona quando é manuseado ou retirado do fundo do armário, causa prazer a quem confeccionou a pasta.

\section{Referências bibliográficas}

ARQUIVO, Pessoal da Ex-aluna. Pasta A-Z. Nova Esperança, 1983.

ARQUIVO, Pessoal da Ex-aluna. Pasta A-Z. Nova Esperança, 1988.

ARQUIVO, Pessoal da Ex-aluna. Pasta A-Z. Nova Esperança, 1989.

ARQUIVO, Pessoal da Ex-aluna. Pasta A-Z. Nova Esperança, 1993.

ATIVIDADE, Enciclopédia de Trabalhos Manuais. São Paulo, Ed. Lisa, s.d.

BACARIN, Lígia Maria Bueno Pereira. O movimento de arte-educação e o ensino 
de arte no Brasil : história e política. Dissertação (Mestrado em Educação) - Maringá, PR : [s.n.], 2005.

BARBOSA, Ana Mae. Arte-Educação no Brasil. Das origens ao modernismo. São Paulo: Perspectiva/Secretaria d Cultura, ciências e Tecnologia do Estado de Dão Paulo, 1978.

BARBOSA, Ana Mae. Arte-Educação no Brasil Realidade hoje e expectativas futuras $^{*}$ Estud. av. vol.3 no.7 São Paulo Sept./Dec. 1989 Disponível em: http://www.scielo. br/pdf/ea/v3n7/v3n7a10.pdf. Acesso em dez de 2012.

BARBOSA, Ana Mae. Teoria e prática da Educação Artística. 14a ed. São Paulo: Cultrix, 1995.

BARBOSA, Ana Mae. Tópicos utópicos. Belo Horizonte: C/Arte, 1998.

BARBOSA, A. M.(org.) Inquietações e mudanças no ensino da arte. $3^{\text {a }}$ ed. São Paulo: Cortez, 2007.

BARBOSA, Ana Mae. John Dewey e o Ensino da Arte no Brasil. 6a Ed. São Paulo: Cortez, 2008.

BARBOSA, Ana Mae; CUNHA, Fernanda Pereira da. (Orgs.). A abordagem triangular no ensino das artes e culturas visuais. São Paulo: Cortez, 2010a.

BARBOSA, Ana Mae. A imagem no ensino da arte: ano oitenta e novos tempos. $8^{\mathrm{a}}$ Ed. - São Paulo: Perspectiva, 2010.

BARBOSA, Ana Mae. Ensino da Arte: memória e história. (Org.). São Paulo: Perspectiva, 2011.

BITTENCOURT, Circe Maria Fernandes. Disciplinas escolares: história e pesquisa. In: OLIVEIRA, Marcus Aurélio Taborda de; RANZI, Serlei Maria Fischer (orgs.). História das disciplinas escolares no Brasil: contribuições para o debate. Bragança Paulista: EDUSF, 2003. p. 9-38.

CHARTIER, Roger. Do códice ao monitor: a trajetória do escrito. Estud. av., Ago 1994, vol.8, nº.21, p. 185-199. ISSN 0103-4014 - www.sielo.br

CHARTIER, Roger. Os desafios da escrita. Tradução de Fúlvia M. L. Moretto. São Paulo: Ed. UNESP, 2002

CHERVEL, A. História das disciplinas escolares: reflexões sobre um campo de pesquisa. PA: Teoria \& Educação, n. 02, 1990

FERRAZ, Maria Heloisa Corrêa de Toledo; FUSARI, Maria Felisminda de Rezende. Arte na educação escolar. São Paulo: Cortez, 2001.

FORQUIN, Jean Claude. Escola e Cultura. Porto Alegre: Artes Médicas, 1993. 
JULIA, Dominique. A Cultura Escolar como objeto histórico. Gizele de Souza (Trad.). Rev. Bras. de História da Educação. Editora Autores Associados. Campinas, SP, 2001

LE GOFF, Jacques. História e Memória. 5ª ed. Campinas: Editora UNICAMP, 2003.

LOPES, Eliane Marta T., GALVÃO, Ana Maria de Oliveira. História da Educação. Rio de Janeiro: DPA Editora, 2001.

LÜDKE, Menga e ANDRÉ, Marli E. D. A. Pesquisa em educação: abordagens qualitativas. São Paulo: E.P.U., 1986.

NEVES, Fátima Maria. A história da educação no Brasil - a trajetória de um campo de ensino e pesquisa. In: ROSSI, E.; RODRIGUES, E.; NEVES, F. (Orgs.) Fundamentos Históricos da Educação no Brasil. 2. ed. Maringá, PR: Eduem, 2009b. p. 13-29.

NEVES, F. M. A utilização do cinema enquanto recurso pedagógico: algumas considerações. Revista Unimar, Maringá, v. 19, n. 1, p. 214-225, mar. 1997.

PARANÁ. Relatório do Parecer no 004/86, em anexo à Deliberação n. ${ }^{\circ}$ 031/86 1986. Disponível em: http://www.nre.seed.pr.gov.br/paranavai/arquivos/File/Del_3186_ Incineracao_Doc.pdf. Acesso em: 20 de ago. de 2012.

PARANÁ, Estado do. Currículo Básico para a Escola Pública do Estado do Paraná. Secretaria de Estado da Educação Superintendência de Educação Departamento de Ensino Fundamental. Curitiba, 2003. (versão eletronica).

PARANÁ. Secretaria de Estado da Educação. Diretrizes Curriculares de Arte para os anos finais do Ensino Fundamental e para o Ensino Médio. Curitiba: SEED, 2008.

PARANÁ, COLÉGIO ESTADUAL SÃO VICENTE DE PAULA. Livro Ata de Termo de exercício, da Escola Normal Colegial Estadual São Vicente de Paula. 1971 - 1978 .

PARANÁ, COLÉGIO ESTADUAL SÃO VICENTE DE PAULA. Livro de Frequência e Controle de Notas: Disciplina de Educação Artística, Curso Normal Colegial. Nova Esperança. 1971 a 1978

PARANÁ, COLÉGIO ESTADUAL SÃO VICENTE DE PAULA. Livro Registro: Disciplina de Educação Artística, Curso Magistério. Nova Esperança. 1979 a 1997.

PARANÁ,COLÉGIO ESTADUAL SÃO VICENTE DE PAULA. Dados referentes ao Colégio. In: . Ata do projeto de implantação da Reforma de Ensino Regular do II Grau. 1976.

PARANÁ. Vídeo - Sistemas de Videocassete em audiovisual, Proposta Pedagógica do Vídeo Escola, Texto apostilado da SEED:1-7,jun, 1988.

SALAS, Clúdia Jaquebede. Motivos Artísticos e Educacionais. Uberlândia: comercial Claranto LTDA, 1973. 
SILVA, Maria Betânia e. A inserção da arte no currículo escolar (Pernambuco, 1950-1980). Dissertação (Mestrado em Educação). Recife: UFPE, 2004.

SILVA, Maria Betânia e. Escolarizações da Arte: dos anos 60 aos 80 do século xx (Recife - Pernambuco). Tese, (Doutorado em Educação, Conhecimento e Inclusão Social) - Faculdade de Educação da Universidade Federal de Minas Gerais. Belo Horizonte, MG, 2010.

STEPHANOU, M.; BASTOS, M. H. C. (Orgs.). Histórias e Memórias da Educação no Brasil. Vol. 3. Petrópolis: Vozes, 2005. p.296-323.

STORI, Regina. As Diretrizes Curriculares de Arte do Estado do Paraná: uma análise dos fundamentos e da gestão do ensino de música em Ponta Grossa/Pr (2003-2010). 2011. 190f. Dissertação (Mestrado em Educação) - Universidade Estadual de Ponto Grossa, 2011. 